\title{
INOVAÇÃO NO ENSINO: LETRAMENTO CRÍTICO NO SMARTPHONE EM SALA DE AULA DE LÍNGUA PORTUGUESA
}

\section{INNOVATION IN EDUCATION: CRITICAL LITERACY USING SMARTPHONES IN THE PORTUGUESE LANGUAGE LESSON}

\author{
Élida Paulina Ferreira \\ Universidade Estadual de Santa Cruz \\ epferreira@uesc.br \\ Daiane Conceição Simões Santos \\ Universidade Estadual de Santa Cruz \\ daysimoes1@hotmail.com
}

\begin{abstract}
RESUMO: A escola, que é considerada uma agência de letramento na sociedade atual, tem sido progressivamente influenciada pelo avanço tecnológico. No contexto atual, as tecnologias digitais têm proporcionado novas possibilidades de interação social e novos gêneros textuais têm ganhado visibilidade. Essa conjuntura, consequentemente, demanda que sejam desenvolvidas em sala de aula habilidades específicas que correspondam à construção da competência leitora e do letramento crítico. A grande circulação de informações que ocorre diariamente por meio da internet requisita, para o exercício pleno da cidadania, o desenvolvimento da criticidade e da reflexão por parte dos sujeitos sobre as várias possibilidades de sentidos e ideologias presentes nos textos. Neste estudo, refletimos sobre a importância de os jovens estudantes desenvolverem o letramento crítico na escola e apresentamos resultados de pesquisa em sala de aula em que foi utilizado o smartphone como recurso tecnológico visando à leitura e à produção de memes. A pesquisa consistiu basicamente de três momentos: aplicação de questionário de levantamento de dados sobre uso de recursos digitais pelos alunos, aplicação de Sequência Didática e aplicação de questionário final para colher a avaliação dos alunos sobre a experiência vivida. Esperamos com esses resultados de pesquisa contribuir para o desenvolvimento de estudos acerca do letramento crítico, na área de Linguística Aplicada ao ensino da língua portuguesa.
\end{abstract}

PALAVRAS-CHAVE: letramento crítico; multiletramentos; smartphone; memes.

ABSTRACT: As one of the agencies of literacy in the current society, the school has been progressively influenced by the technological advance. In the current context, digital technologies create new possibilities for social interaction as well as it gives visibility to new textual genres. This conjuncture, consequently, demands that the critical literacy to language teaching is developed in the school, since a great amount of information circulates daily through the internet, ordering the development of critical reflection on the various possibilities of meanings and ideologies circulating in texts. In this paper, we reflect on the importance of young students developing critical literacy in school, and we present classroom research results in which the smartphone was used as a tool for reading and producing memes. The research followed three steps: 1) First, we applied a questionnaire for gathering information from respondents about their use of digital tools; 2) Then we 
developed a Didactic Sequence; 3) Third, we applied another questionnaire for collecting information about respondents' perception of the experience. We hope these research results may contribute to the development of studies about critical literacy in the area of Applied Linguistics to teaching Portuguese.

KEYWORDS: critical literacy; multiliteracies; smartphone; memes.

\section{Introdução}

Promover aulas que visem estimular o letramento crítico, por meio de atividades que envolvam a leitura e a escrita, utilizando uma tecnologia digital móvel, é um processo estimulante e desafiador para o professor de língua portuguesa, pois algo novo geralmente suscita inquietações.

Nesse contexto desafiador, auxiliar o desenvolvimento do letramento crítico durante as aulas de língua portuguesa implica incentivar os alunos a terem uma postura crítica frente aos diversos textos com os quais se deparam diariamente, no uso dos seus smartphones, particularmente com memes, que é o gênero digital abordado neste estudo. Ademais, é função da escola promover a construção desse letramento que é emergente na sociedade tecnológica atual. Implica, também, incentivar o reconhecimento de que todos os textos que circulam nos ambientes virtuais viabilizados pelo smartphone são representações da realidade e que esses alunos, como cidadãos, precisam questionar a sua produção, a sua intencionalidade, bem como a veracidade dos fatos ou das ideias veiculadas, com a compreensão de que podem aceitá-los, negá-los ou reconstruí-los, ampliando a sua crítica e participação no mundo.

Por isso, a pesquisa incorporou espaços inovadores de leitura e escrita na aula de língua portuguesa, partindo da leitura e da produção de memes na tela do smartphone. Este estudo buscou ressignificar o uso desse suporte, aliando-o à perspectiva dos multiletramentos e do letramento crítico, fato que implica o incentivo à construção de sentidos e a produção de textos multimodais em ambiente digital. Esse estudo buscou, também, estabelecer uma parceria entre escola e universidade, construindo instrumentos que podem contribuir para a superação dos desafios no processo de ensinoaprendizagem presente na contemporaneidade.

Este artigo está organizado em duas seções principais. Na primeira, abordamos a concepção de letramento crítico na qual nos amparamos. Na segunda parte, apresentamos uma intervenção em sala de aula em que fizemos uso do smartphone na escola como recurso pedagógico para o desenvolvimento do letramento crítico, a partir da leitura e da escrita de memes. Apresentamos, também, os principais resultados da intervenção e as possíveis contribuições para os estudos de linguagem, em particular para a linguística aplicada crítica.

\section{O letramento crítico e os desafios (im)postos para a escola}

A escola, como uma das principais agências de letramentos, encontra-se diante de dois desafios: o primeiro é desenvolver métodos de ensino e aprendizagem que atendam aos requisitos da sociedade tecnológica atual e o segundo é conduzir seus alunos a 
desenvolverem a reflexão crítica sobre a própria realidade, partindo do uso pedagógico das tecnologias digitais dentro e fora da escola. Tais princípios convergem para nomear um tipo de letramento que alguns autores, como Kress e Van Leeuwen (1996, 2001a, 2001b), conceituam como letramento crítico visual, que está ligado à concepção de multiletramentos e ao que Hodge e Kress (1998) chamam de semiótica social.

O letramento crítico é um conceito recente no campo da linguagem e do ensino de línguas, mas se mostra um campo fértil na contemporaneidade. Segundo Santos Costa (2013, p. 40),

\begin{abstract}
O conceito de letramento crítico ganhou campo de pesquisa durante os anos 1980 e 1990. [...] Para alguns, o conceito de letramento crítico deriva principalmente do trabalho de críticos teóricos do discurso e do seu reconhecimento de que a linguagem não é um campo neutro. Para outros, noções de letramento crítico têm suas origens na Teoria de Gêneros Textuais e nas análises da Linguística Sistêmico Funcional, como uma crença de que o simples conhecimento da linguagem e as diversas opções de texto permite atingirmos a coesão social, elemento útil para estudantes de línguas. Para outros ainda, a teoria de letramento crítico emerge da noção freireana em relação à importância de analisar as relações e campos da ideologia, do poder social, cultural e econômico que envolvem tanto quem ensina quanto quem aprende.
\end{abstract}

Santos Costa, no excerto acima, evidencia que o letramento crítico relaciona-se à consciência crítica social dos alunos sobre a circulação de textos e de suas condições de produção e impacto na sociedade. Nesse sentido, adota-se uma ideia de letramento que envolve os variados meios semióticos de que o sujeito faz uso para construir sentido. Sobre essa concepção de letramento, Santos Costa (2013, p. 40-41) também comenta que:

\begin{abstract}
Os educadores de letramentos visuais como: Messaris (1994), Hodge e Kress (1988) Kress e Van Leeuwen (1996), e outros, e organizações como a Associação Internacional de Letramento Visual americana estão entre aqueles que têm enfatizado a centralidade cada vez maior do visual na paisagem contemporânea de comunicações e no ensino. Eles mostraram como as imagens visuais de todos os tipos são cada vez mais utilizadas para representar significados, ideias e sentimentos, muitas vezes em combinações complexas e orquestradas com palavras, sons e movimentos.
\end{abstract}

Seguindo a mesma linha de raciocínio, Takaki e Maciel (2015) esclarecem que autores como Kalantis, Cope e Kress questionaram as primeiras concepções acerca da palavra letramento, considerando muito restrita sua definição associada somente às habilidades da escrita, privilegiando apenas a modalidade verbal, definição considerada insuficiente para analisar e compreender o modo como os sujeitos lidam com os sentidos nas suas práticas cotidianas.

De acordo com Takaki e Maciel (2015), o letramento crítico vincula-se à aprendizagem e serve de base para estudos que investigam práticas que envolvem o uso pedagógico de tecnologias em sala de aula. E reforçam, ainda, a importância de se entender a relação entre práticas sociais e as mais diversas linguagens em uso. Sob esse prisma, justificam-se os estudos sobre os novos letramentos, destacando nessa pesquisa 
o letramento crítico, e a sua aplicação em sala de aula de língua portuguesa.

Pode-se afirmar que a escola, como já foi dito anteriormente, enquanto agenciadora de letramentos, tornou-se um espaço em que se deve dialogar permanentemente com as mudanças sociais promovidas pelas tecnologias digitais. Para Kress (2007 apud TAKAKI; MACIEL, 2015, p. 18),

se o perfil do público a que serve a escola mudou, vai ser apropriado transformar também a escola e o papel da educação formal; não somente trocando de ferramentas para realizar as mesmas práticas, mas reformulando a pedagogia e as relações que se estabelecem nesse ato social chamado aula.

É preciso ressaltar que o público adolescente que a escola atende é denominado por estudos atuais como a geração Z. Esse público adolescente nasceu na era tecnológica (PALFREY; GASSER 2011), conviveu desde muito cedo com as inovações tecnológicas e isso influenciou decisivamente o seu letramento e as suas práticas sociais. Essa "era digital" mudou a forma como os sujeitos vivem, se relacionam e, certamente, como aprendem, poderíamos acrescentar. $\mathrm{Na}$ escola essa realidade é muito evidente. Basta observarmos os adolescentes e seu modo de se comportar, como estudam, escrevem e interagem de uma maneira bem diferente de como se comportavam os adolescentes das gerações anteriores. Estão conectados nas redes sociais o tempo todo, leem blogs em vez de revistas ou jornais, fazem amizades, paqueram, namoram e estudam online e até para comunicar-se com familiares preferem mandar uma mensagem de texto por aplicativos, como o famoso WhatsApp e outros não tão famosos, como o Telegram (aplicativo usado em nossa intervenção). Ou seja, as suas interações sociais são mediadas pelas tecnologias digitais. Então, a escola pós-contemporânea precisa se adaptar para corresponder a esse novo perfil de sujeito, se atualizando e se credenciando para auxiliá-lo a desenvolver, ainda mais, o letramento digital e crítico.

Para Takaki (2012, p. 42), estudar o letramento crítico implica considerar que "o conhecimento não é natural ou neutro, é sempre baseado em regras discursivas de uma determinada comunidade, e é, portanto, ideológico". Além disso, ela realça que o significado textual é sempre múltiplo, contestado, historicamente situado e construído em meio a diferentes relações de poder. Sendo assim, é preciso que a escola, ao trabalhar o letramento crítico, aborde os processos de leitura e de escrita como construção de sentidos, sempre vinculados a um determinado contexto sócio-histórico, econômico e político e às relações de poder que constroem o mundo.

Nessa ótica, os alunos devem ser auxiliados a desenvolver sua criticidade em relação aos textos que circulam nos ambientes virtuais, identificando quais vozes sociais estão presentes neles, aceitando-as ou refutando-as, conforme sua própria visão de mundo. Nessa ótica, o conhecimento é construído de forma que o sentido do texto é sempre múltiplo e depende do contexto em que ele é socialmente interpretado.

De acordo com Takaki (2012), desenvolver o letramento crítico implica conduzir os estudantes a questionar as visões de mundo disseminadas nos textos, as vozes de determinados grupos sociais que podem estar sendo ou não atendidas a partir desses textos, questionando assim estereótipos e ideologias vigentes. Nesse ponto de vista, a leitura também significa participação social e construção de identidade. Takaki (2012, p. 43) acrescenta que "o letramento crítico prima por uma abordagem que considera o 
processo de leitura como uma construção de significados atrelados ao contexto histórico, político e econômico, as relações de poder como uma forma de vir a conhecer o mundo e a si mesmo".

Assim, compreendemos que, no cenário contemporâneo permeado por artefatos tecnológicos digitais e textos multimodais, estudos como os de Takaki (2012) e de Janks (2016) ganham relevância. No seu modelo de letramento crítico, Janks (2016) destaca as relações entre língua e poder, discurso e poder, diversidade, acesso, design e redesign textual. Essa abordagem compreende, na sua visão, a apropriação da linguagem pelo sujeito, como não neutra e atrelada ao seu processo social e ao exercício de cidadania.

Ao abordar como a língua e o discurso podem ser instrumentos de poder, a autora afirma que muitas das relações de poder são estruturadas socialmente, por meio da linguagem. Nesse contexto, a linguagem também pode ser usada para desafiar o status quo, podendo conduzir à transformação social. Nesse sentido, instituições como a escola, a família e a mídia são essenciais, podendo agir na construção de sentidos dos sujeitos, para perpetuar uma organização social excludente ou para contestá-la e transformá-la. Esse seria o papel do letramento crítico. Essa transformação a que Janks (2016) se refere é fundamentada por princípios, por exemplo, de igualdade social, racial, de gênero, de sexualidade e inclusão, que nem sempre são respeitados nas sociedades humanas, de modo geral. Assim, associam-se aos princípios do letramento crítico fatores como a diversidade cultural, que precisa ser respeitada e abordada na escola.

Dessa perspectiva, as ideias de Janks (2016) convergem para o encontro com as ideias de Paulo Freire e sua pedagogia crítica, quando ela afirma que o ato de ler inclui a leitura de mundo, a fim de mudá-lo. Segundo a autora, "como o nosso mundo é construído na e pela linguagem, ela molda nossa compreensão dele, associada ao nosso senso de um eu particular e dos outros" (JANKS, 2016, p. 31). Nesse sentido, ler pode ampliar nossas possibilidades de construção de sentido, ao entrarmos, por meio da leitura, em contato com o nosso eu, com o outro e com o mundo.

Seguindo esse raciocínio, Janks acrescenta que, entre os pressupostos do letramento crítico, há também a questão do acesso a ser considerada. Nesse ponto, ela esclarece que é preciso realizar questionamentos sobre o que ou quem é privilegiado na sociedade. E pensando sobre o contexto escolar é possível lançar questionamentos, levando os estudantes a refletirem sobre aspectos importantes, como, por exemplo, qual a variedade da língua que tem prestígio social, quais são as classes sociais que ocupam determinadas posições na sociedade, que versão da história é ensinada na escola, se as práticas de ensino e aprendizagem na escola atual estimulam mais a competição ou a colaboração, quem se beneficia com a disseminação de determinado texto oral ou escrito. Esses são apenas exemplos de questionamentos que podem levar as pessoas a compreenderem a que elas têm ou não acesso, social e culturalmente. A conscientização pode, assim, levar à ação e, possivelmente, transformação.

Também nos interessou, neste estudo, o conceito de design, utilizado por Janks (2016). Trata-se da ação do leitor e do produtor de textos, de se manterem atentos, de modo a reconhecerem como se posicionam em relação a determinado assunto ou texto. Além disso, trata-se também de ampliar a compreensão sobre como são elaborados os textos que circulam socialmente e ter noção sobre as diversas possibilidades de construção de sentido. É preciso oportunizar esse exercício de construção e reconstrução de sentidos nas práticas de ensino e aprendizagem. Assim, nessa construção do 
letramento crítico da realidade, os estudantes podem "fazer" o design e o redesign dos seus próprios textos e dos textos de outros.

Quando os alunos interpretam e avaliam textos, empreendem os próprios sentimentos, valores e as respostas às ideias apresentadas. Do mesmo modo, fazem de suas próprias respostas aos textos um fator integrante da experiência de leitura cultural. De acordo com Freire (1987, p. 26), "quanto mais as massas populares desvelam a realidade objetiva e desafiadora sobre a qual elas devem incidir sua ação transformadora, tanto mais se 'inserem' nela criticamente". Acreditamos que é nesse sentido que deve seguir a educação, como instrumento de transformação. Seguindo essa mesma linha de raciocínio, segundo Takaki (2012, p. 13),

\begin{abstract}
a história tem ensinado que letramentos referem-se a um conjunto de práticas culturais que são construídas e reconstruídas por interesses socioculturais em permanente conflito, em meio às relações de poder, descartando a expectativa de neutralidade convencionalizada por leituras tradicionais e grafocêntricas [...]. Assim sendo, os textos são estruturados por domínios socioeconômicos, representando, portanto, as perspectivas de alguns grupos sociais ao mesmo tempo em que acabem silenciando outras interpretações. Nesse sentido, percebe-se que a natureza hipermodal da linguagem permite instanciarmos outros posicionamentos, evidenciando as visões dominantes e, ao mesmo tempo, possibilitando que esses sejam criticados e reinterpretados constantemente. A tarefa de reinterpretar, em si, constrói-se em teoria, pois revela a produção de conhecimento.
\end{abstract}

Assim, na contemporaneidade, as interações sociais dos estudantes hiperleitores no mundo digital também interferem na construção de suas identidades, na fluidez dos discursos disseminados pela internet. Então, é necessário que haja um trabalho pedagógico que permita a reflexão sobre a natureza flexível da linguagem que circula nesses ambientes digitais, estimulando os estudantes hiperleitores a questionarem os discursos com os quais estão em contato diariamente, interpretando e reinterpretando, construindo, desconstruindo e reconstruindo. Isso quer dizer que as interações digitais têm proporcionado formas inovadoras de (re)construção de sentido que inevitavelmente irão incidir na formação dos cidadãos. Isso requer inovações metodológicas nas instituições escolares.

Conforme ressalta Takaki (2012, p. 51), o letramento crítico pode conscientizar o leitor sobre o fato de que "os textos são produzidos, distribuídos e interpretados de acordo com os objetivos, práticas e interesses socioeconômicos e culturais que concorrem para serem legitimados e mantidos". A autora também nos chama atenção para o fato de que os novos letramentos impulsionados pelo uso das TIC (Tecnologias de Informação e Comunicação) são requeridos nas sociedades em meio a uma variedade e simultaneidade de necessidades e interesses interconectados: individuais, coletivos, nacionais, transnacionais e globais.

Nessa perspectiva, desenvolver um trabalho tendo como foco o letramento crítico a partir da tela de um suporte de interação significa incentivar os estudantes de língua portuguesa a se posicionarem criticamente diante dos discursos em circulação e a aguçarem o olhar sobre os textos em circulação, considerando seus aspectos culturais, contextuais, ideológicos, políticos e econômicos. Conectada com esses novos estudos de linguagem, viabilizados pela linguística aplicada, encontra-se esta pesquisa, cuja descrição e resultados passamos a apresentar. 


\subsection{O uso do smartphone e a construção do letramento crítico na escola}

Após a aprovação da pesquisa pelo Comitê de Ética em Pesquisa da Universidade Estadual de Santa Cruz, em dezenove de outubro de 2016, a intervenção foi iniciada na Escola Municipal do Banco da Vitória, no bairro Banco da Vitória, em Ilhéus-Bahia. Essa escola integra a rede municipal de Ilhéus-BA, ofertando o Ensino Fundamental II, que é objeto dessa pesquisa (duas turmas do nono ano). Além disso, a unidade escolar foi escolhida por apresentar histórico de parcerias com a academia e dispor de infraestrutura adequada para a realização da pesquisa, tal como a existência e disponibilidade de internet sem fio. Ademais, constitui-se como o local de atuação da docente pesquisadora, há 10 (dez) anos.

No que se refere aos aspectos metodológicos, optamos pela pesquisa de natureza mista, nesse caso bibliográfica, intervencionista, exploratória e baseada na pesquisaação, com coleta de dados pela observação participante e sistemática, por meio de questionários, captura de tela e análise qualitativa de dados.

Ressaltamos que a parceria entre a escola e a universidade, propiciada pela prática de pesquisa adotada, pode oportunizar um espaço para a realização de práticas colaborativas, processo no qual os participantes assumem um papel de produtores de conhecimento, atuando na construção de sentidos no mundo.

Esta pesquisa focalizou o uso do smartphone, hoje ainda considerado como um problema em sala de aula. Os resultados apontam impactos positivos e significativos para todos os participantes da pesquisa, pois o conhecimento pôde ser construído pelas ações coletivas dos participantes, aliando assim a pesquisa e o processo de ensinoaprendizagem.

$\mathrm{Na}$ escola, a pesquisa foi apresentada, assim como suas fases, para esclarecer aos participantes sobre os protocolos éticos de pesquisa com seres humanos e sobre 0 processo de consentimento livre e esclarecido. Após a realização do seminário de apresentação, os alunos receberam o Termo de Consentimento Livre e Esclarecido, TCLE, disponibilizado pelo Comitê de Ética em Pesquisa, para que entregassem aos pais ou responsáveis para concordância e assinatura. Esses estudantes foram orientados a informar aos seus pais ou responsáveis sobre a importância da pesquisa e de sua participação, bem como sobre a autorização do uso do smartphone em sala de aula, para os que possuíam esse aparelho. Também foram orientados a informar-Ihes que a direção da escola e a docente pesquisadora estavam à disposição no ambiente escolar, em período de aula, para maiores esclarecimentos, caso houvesse a necessidade.

A pesquisa consistiu de basicamente três momentos: aplicação de questionário de levantamento de dados, aplicação de Sequência Didática (a ser detalhada mais adiante) e aplicação de questionário final para colher a avaliação dos alunos sobre a experiência vivida.

O questionário inicial tinha os seguintes objetivos: (1) identificar a relação dos alunos com o uso do aparelho smartphone, suas expectativas e modo de uso no cotidiano; e (2) um levantamento sobre a frequência de uso desse aparelho no contexto escolar, a frequência de acesso à internet e as finalidades desse uso pelos alunos.

O questionário utilizado na fase final, após a aplicação da Sequência Didática, objetivou: (1) identificar a impressão dos alunos com relação ao impacto do uso do 
smartphone nas aulas de língua portuguesa; (2) identificar que atividade se caracterizou como mais significativa para os alunos; (3) perceber a relevância da experiência da participação do aluno no grupo online do Telegram para a sua formação escolar; e (4) realizar uma avaliação crítica do projeto na visão dos alunos.

Pelo fato de as estratégias de ensino e aprendizagem terem sido planejadas para ocorrerem no grupo do aplicativo Telegram, as capturas de tela representaram um dado para esta pesquisa. Esse procedimento visou investigar como os alunos utilizavam a linguagem, como puderam construir sentidos e exercer a reflexão crítica sobre os usos da linguagem na discussão que partiu da leitura de "memes" no ambiente virtual, tendo em vista a compreensão e construção de sentidos. Destacamos, ainda, que, nesse ambiente de grupo no aplicativo Telegram, procuramos ocultar a foto de perfil dos usuários e os seus nomes, de modo a assegurar a privacidade dos participantes.

No grupo criado no Telegram, com os alunos participantes da pesquisa, foi aplicada a Sequência Didática ao longo de 10 (dez) horas aulas sequenciais, utilizando estratégias de ensino e aprendizagem pautadas no letramento crítico.

De posse dos dados organizados por meio dos procedimentos descritos, foi feita uma compilação no intuito de realizar uma interpretação qualitativa pela pesquisadora, adotando a técnica de triangulação dos dados. Os dados qualitativos foram interpretados a partir das reações dos alunos, percebidas na dinâmica de interação no grupo, por meio das capturas de telas, bem como pelas respostas dos alunos participantes às perguntas dos questionários, como a avaliação dos aspectos positivos e negativos, críticas, comentários e demais pareceres.

Nesse estudo, foi utilizada a observação sistemática participante, estruturada pelo papel da pesquisadora como mediadora do grupo no Telegram, promovendo as discussões temáticas e delimitando as atividades, em ações conjuntas com o grupo, visando estimular a reflexão sobre os usos da linguagem em um suporte digital associado ao processo de ensino-aprendizagem.

Construímos e aplicamos uma Sequência Didática equivalente a 10 (dez) aulas sequenciais organizadas em 5 (cinco) etapas: a) apresentação inicial; b) produção inicial; c) módulo 1; d) modulo 2; e e) produção final. Tal organização foi baseada no modelo de Dolz, Noverraz e Schneuwly (2004). O período de atividades correspondeu a duas semanas, sendo que a carga horária de cada semana correspondeu a 5 (cinco) aulas. Cada etapa correspondeu a duas aulas.

Para nortear a aplicação da Sequência Didática, escolhemos o gênero digital meme, advindo das novas práticas de interação nos suportes tecnológicos digitais de leitura e de escrita, por acreditar que é importante que ele seja alvo de reflexão pelo aluno sobre o uso da língua materna e que, por meio dele, pode-se desenvolver a criticidade e a autonomia em grupos online no smartphone.

Além da leitura e da produção escrita de diálogos norteados a partir da temática em destaque no gênero digital meme, questões foram lançadas de acordo com os descritores da Matriz de Referência de Língua Portuguesa para o Ensino Fundamental, amparada nos Parâmetros Curriculares Nacionais de Língua Portuguesa (PCNs), estimulando a construção de sentidos e a formação de opiniões sobre as temáticas levantadas. A matriz traz a relação entre os descritores e habilidades estabelecidos para avaliar os alunos do $9^{\circ}$ ano do Ensino Fundamental. Os descritores aparecem dentro de tópicos que 
contemplam habilidades a serem desenvolvidas. Sendo eles:

Quadro 1: Matriz a partir da Matriz de Referência de Língua Portuguesa para o 9. ano do Inep.

\begin{tabular}{|c|c|}
\hline $\begin{array}{l}\text { Tópico I } \\
\text { procedimentos }\end{array}$ & Descritores \\
\hline & D1 localizar informações explícitas em um texto. \\
\hline & D3 inferir o sentido de uma palavra ou expressão. \\
\hline & D4 inferir uma informação explícita em um texto. \\
\hline & D6 identificar o tema de um texto. \\
\hline & D14 distinguir um fato da opinião relativa a esse fato. \\
\hline $\begin{array}{l}\text { Tópico IV } \\
\text { coerência e } \\
\text { coesão no }\end{array}$ & Descritores \\
\hline & $\begin{array}{l}\text { D2 estabelecer relações entre partes de um texto, identificando repetições } \\
\text { ou substituições que contribuem para a continuidade de um texto. }\end{array}$ \\
\hline & D7 identificar a tese de um texto. \\
\hline & $\begin{array}{l}\text { D8 estabelecer a relação entre a tese e os argumentos oferecidos para } \\
\text { sustentá-la. }\end{array}$ \\
\hline & $\begin{array}{l}\text { D10 estabelecer relação causa/consequência entre partes e elementos do } \\
\text { texto. }\end{array}$ \\
\hline & $\begin{array}{l}\text { D15 estabelecer relações lógico-discursivas presentes no texto, marcadas } \\
\text { por conjunções, advérbios etc. }\end{array}$ \\
\hline $\begin{array}{l}\text { tópico V } \\
\text { relações entre } \\
\text { recursos } \\
\text { expressivos e }\end{array}$ & Descritores \\
\hline & D16 identificar efeitos de ironia ou humor em textos variados. \\
\hline & $\begin{array}{l}\text { D18 identificar o efeito de sentido decorrente a escolha de uma } \\
\text { determinada palavra ou expressão. }\end{array}$ \\
\hline
\end{tabular}

Na aplicação da Sequência Didática, no tópico "apresentação da situação", alguns memes foram expostos pela pesquisadora, utilizando o aparelho data show e, também, o espaço digital do aplicativo Telegram, visando ativar os conhecimentos prévios dos alunos sobre o gênero. Foi estabelecido um diálogo com a turma sobre os sentidos possíveis do memes apresentados, enfocando os descritores (Quadro 1).

A seguir, selecionamos algumas capturas de tela no intuito de demonstrar como foi a execução da nossa Sequência Didática, aplicada no ambiente digital, com a participação dos alunos e da pesquisadora no grupo online do aplicativo. Na sequência (Figuras 1 e 2), a pesquisadora apresentou o gênero digital meme, provocando uma discussão crítica sobre seus modos de elaboração. 


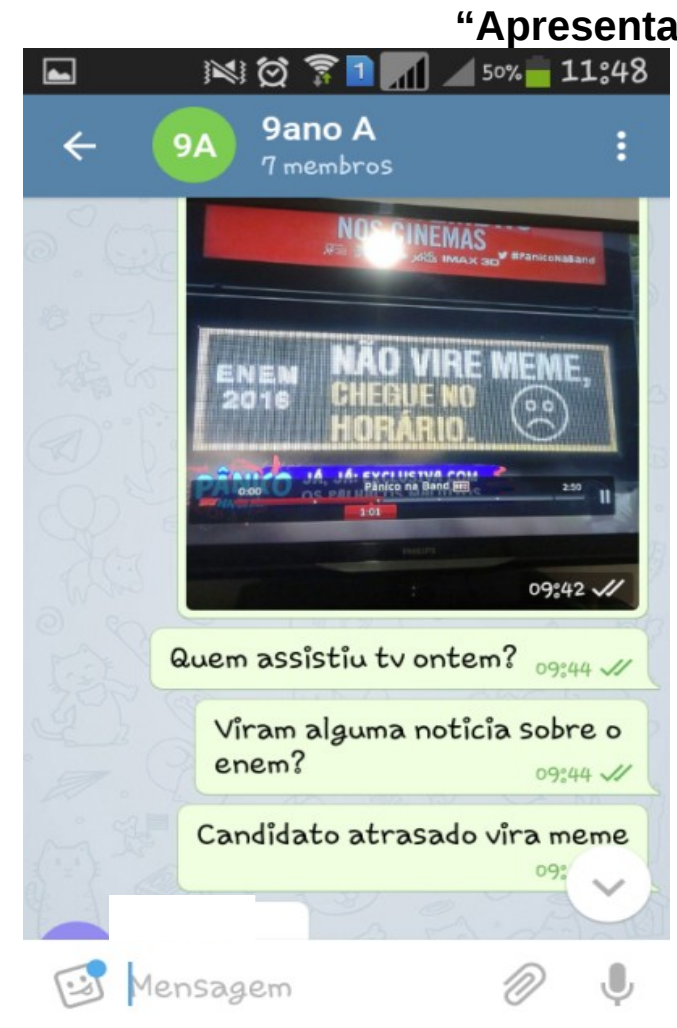

Figure 1: Meme sobre o ENEM.

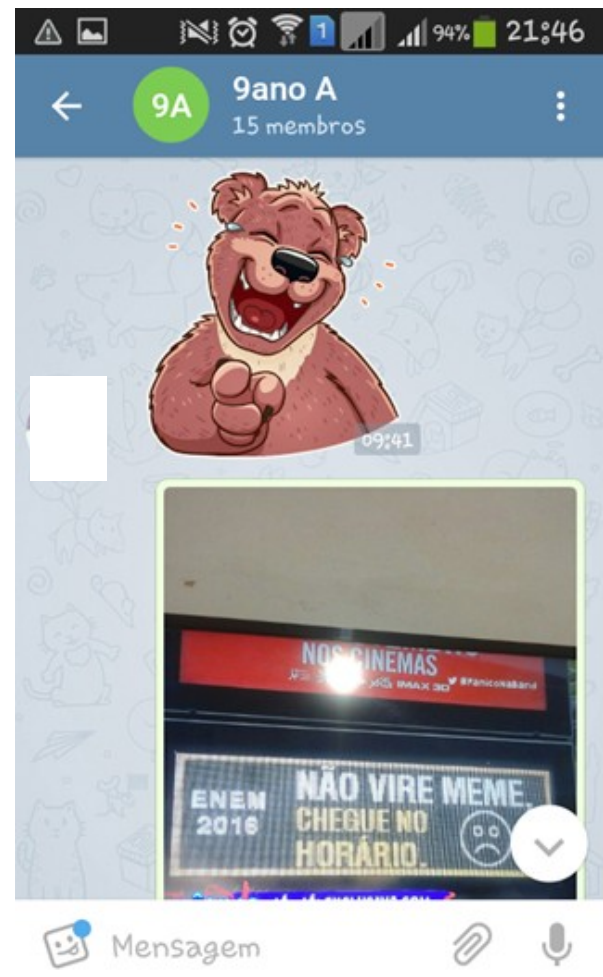

Figure 2: Postagem de aluno.

Fonte: dos autores.

A pesquisadora (Figura 1) postou uma imagem apresentando um meme, referindose ao momento de aplicação de provas do Exame Nacional do Ensino Médio (ENEM 2016). Com essa imagem, o intuito foi de auxiliar os alunos a perceberem o caráter volátil e efêmero do processo de elaboração de um meme.

A referida imagem expressa humor e aconselha os candidatos ao ENEM a não se atrasarem para a realização dessa prova, caso contrário podem virar memes. A discussão prosseguiu no sentido de demonstrar como as pessoas utilizam o smartphone para registrar as situações em tempo real. Em poucos segundos, uma foto, um vídeo, um áudio pode se transformar em objeto de humor e circular nas mídias digitais por meio de aplicativos de informação e comunicação.

Registrou-se a reação bem humorada de um dos participantes da pesquisa (Figura 2) que postou um emoji esboçando um "urso sorrindo", o que demonstra compreensão sobre a situação apresentada. O participante espontaneamente esboçou sua reação utilizando um dos recursos do aplicativo online e, também, outros participantes reagiram com bom humor, afirmando que não queriam ser, dessa forma, transformados em memes. Alguns ainda afirmaram ter receio de realizar esse exame, ou seja, para eles parecia ser difícil.

A partir dessa experiência, os alunos tiveram a oportunidade de ampliar suas possibilidades de percepção e construção de sentidos, ao atuarem como leitores, e, também, como produtores de texto no espaço digital, buscando informações e compartilhando imagens e pontos de vista, além disso, exercitando o respeito à opinião 
do outro. Assim, construindo e reconstruindo, nesse processo, o que pode conduzir ao letramento crítico, confirmando o que a literatura vem discutindo sobre a temática (TAKAKI 2012; JANKS, 2016).

Na sequência (Figuras 3 e 4), outro participante da pesquisa fez uma postagem envolvendo a temática do ENEM:

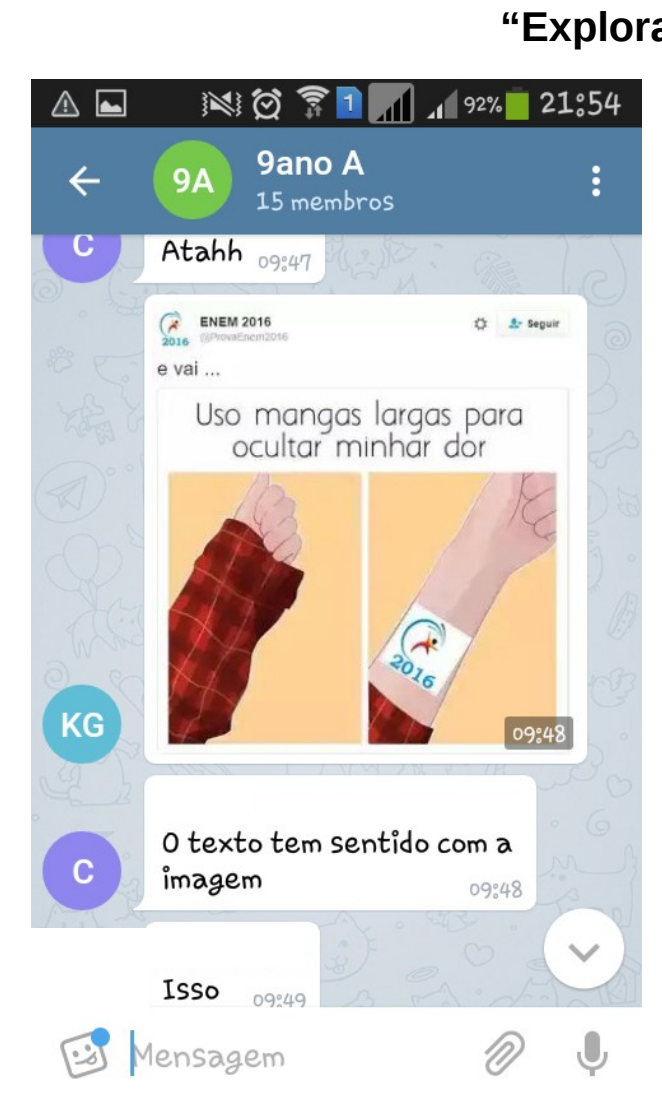

Figure 3: Postagem de aluno.

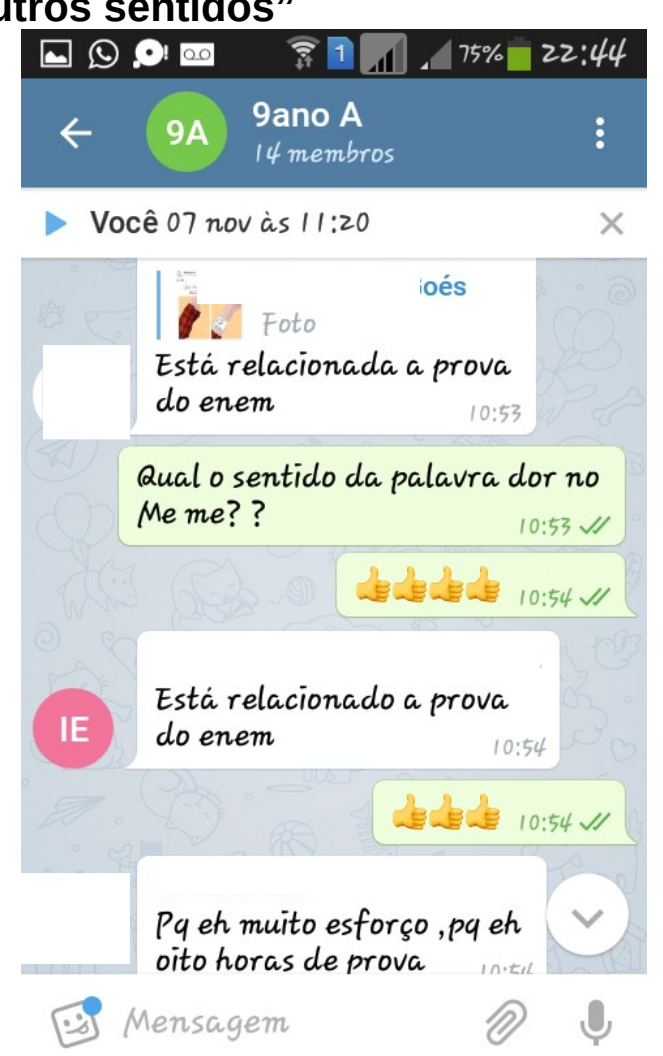

Figure 4: Interação no grupo do Telegram.

Fonte: das autoras.

As Figuras 3 e 4 também fazem parte da etapa da produção inicial, momento em que ocorreu um diagnóstico sobre o domínio e a compreensão dos alunos em relação ao que foi explanado sobre o gênero digital e a temática abordada. Para isso, foi promovida uma discussão no grupo do Telegram, a partir de uma seleção de memes que os próprios alunos pesquisaram e postaram em tempo real. Por exemplo, um aluno postou um meme sobre o ENEM (Figura 3, é apresentada uma imagem de 2016), abordando um aspecto diferente do ENEM, que não fora abordado (Figuras 1 e 2). Para nós, isso demonstra a capacidade de estabelecer outras relações de sentido a partir da temática discutida.

$\mathrm{Na}$ marcação em verde (Figura 4), observa-se que a pesquisadora estimulou a intervenção dos alunos por meio de postagem de comentários online, de forma a que ampliassem a sua leitura do assunto, estabelecendo relações, demonstrando se entenderam a situação de produção das imagens veiculadas no grupo e a coerência das postagens com os assuntos discutidos. Ao analisarmos esses dados, que são resultados 
desta pesquisa, constatamos que nossa proposta de mediar atividades de leitura e de escrita na tela do smartphone é viável e estimulante para os alunos.

A seguir, demonstramos outras etapas da Sequência Didática, os módulos 1 e 2, apresentando outros exemplos da interação entre a pesquisadora e os participantes da pesquisa.

"Memes no contexto político"

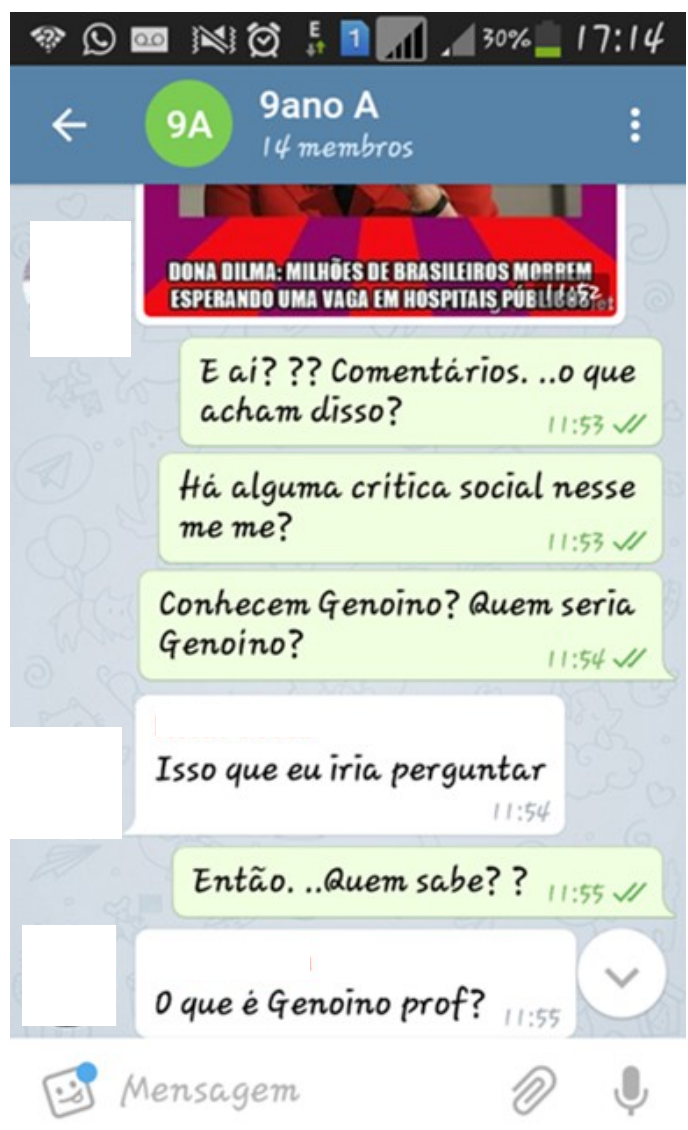

Figure 5: Postagens: Quem é Genoíno?

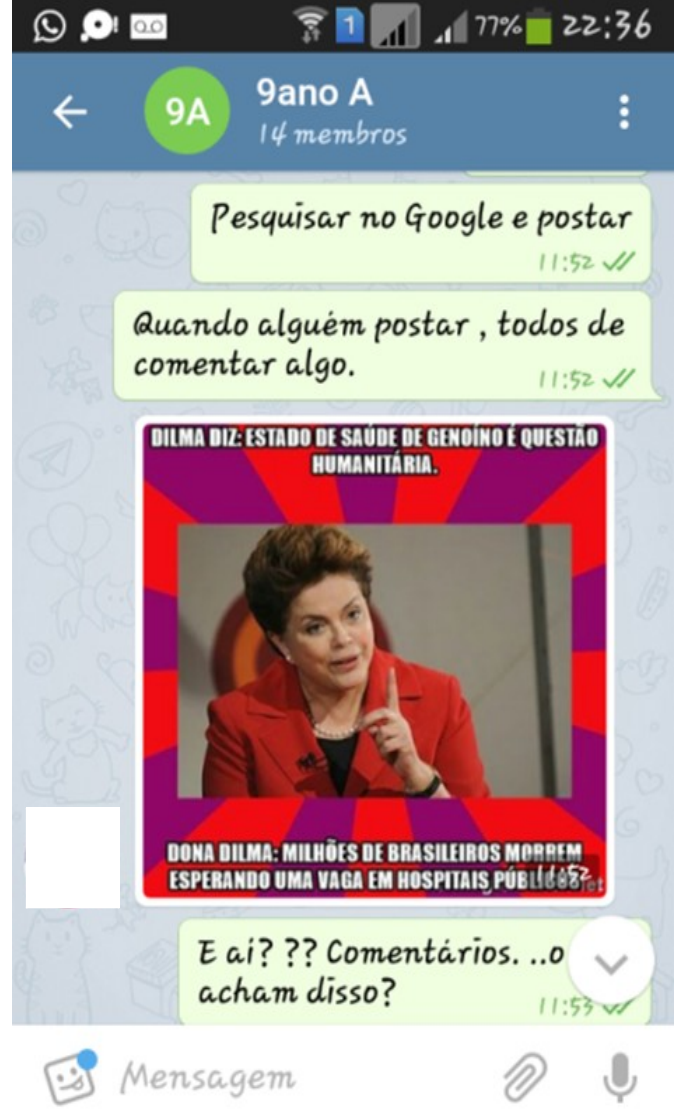

Figure 6: Postagens da pesquisadora.

Fonte: das autoras.

Nos módulos 1 e 2, reforçou-se o trabalho com os descritores específicos da Matriz de Referência de Língua Portuguesa, no intuito de esclarecer dúvidas apresentadas pelos alunos, na produção escrita inicial e chamar a sua atenção para os efeitos práticos, estéticos, cognitivos, para o uso figurado (conotativo) da linguagem no meme e para os efeitos de ironia ou humor. A tarefa consistiu em pesquisar um meme na internet, abordando temas sobre política, educação, saúde, segurança pública, economia etc. Em seguida, compartilhou-se no grupo e comentou-se, com base em perguntas lançadas pela professora pesquisadora, online. As perguntas visaram despertar e favorecer a leitura crítica. As respostas foram escritas no ambiente digital, no espaço do grupo, onde a pesquisadora também estava conectada. A pesquisadora observou as ações sistematicamente, mediando, orientando e esclarecendo dúvidas surgidas durante o processo. 
As capturas de tela selecionadas representam, neste artigo, apenas algumas amostras que consideramos significativas, de acordo com os objetivos da Sequência Didática que planejamos para a pesquisa. As atividades que envolveram a leitura e a produção dos memes na tela do smartphone, por meio do aplicativo Telegram, foram elaboradas com o intuito de demonstrar um exemplo de como o professor de Língua Portuguesa poderia mediar atividades de leitura e produção de texto a partir de memes, contemplando as práticas de interação virtual.

Com a elaboração e aplicação da Sequência Didática, oportunizamos um momento para refletir sobre questões referentes à sociedade atual, a partir da leitura de memes que circulam na internet. Diante dessa ação realizada na escola, espera-se que os alunos compartilhem além dos muros da escola as suas construções de sentido em quaisquer espaços de interação.

A seguir, apresentamos mais algumas capturas de tela nas quais constam postagens dos participantes da pesquisa na execução da Sequência Didática, no módulo 2. Os alunos pesquisaram textos e informações complementares, em sites de busca na internet, com o intuito de esclarecer dados relevantes para a compreensão do sentido da mensagem exposta no meme (Figura 6). Essa hipertextualidade foi possibilitada em todos os momentos pelo acesso à internet, viabilizando a construção dos sentidos presentes nos memes compartilhados, que abordaram assuntos que são de interesse público como a política do Brasil. A seguir, apresentam-se os resultados das pesquisas dos alunos na internet (Figuras 7, 8 e 9), que, para entender o meme (Figura 6), tiveram de buscar saber quem era Genoíno. Outras informações acabaram emergindo, inclusive de fatos já ocorridos.

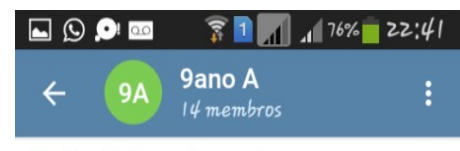

Você 07 nov às 11:20

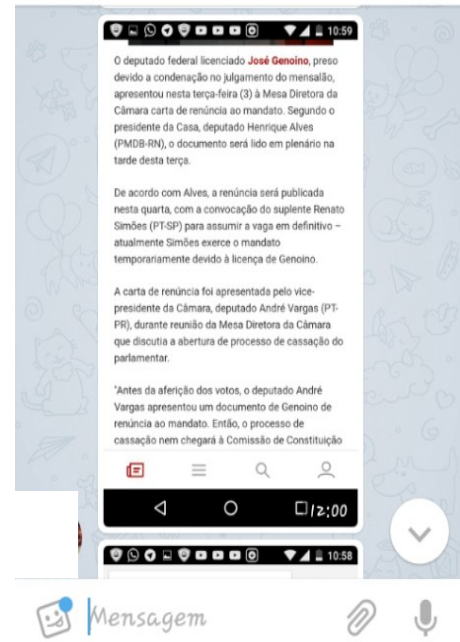

Figure 7: Busca na internet.

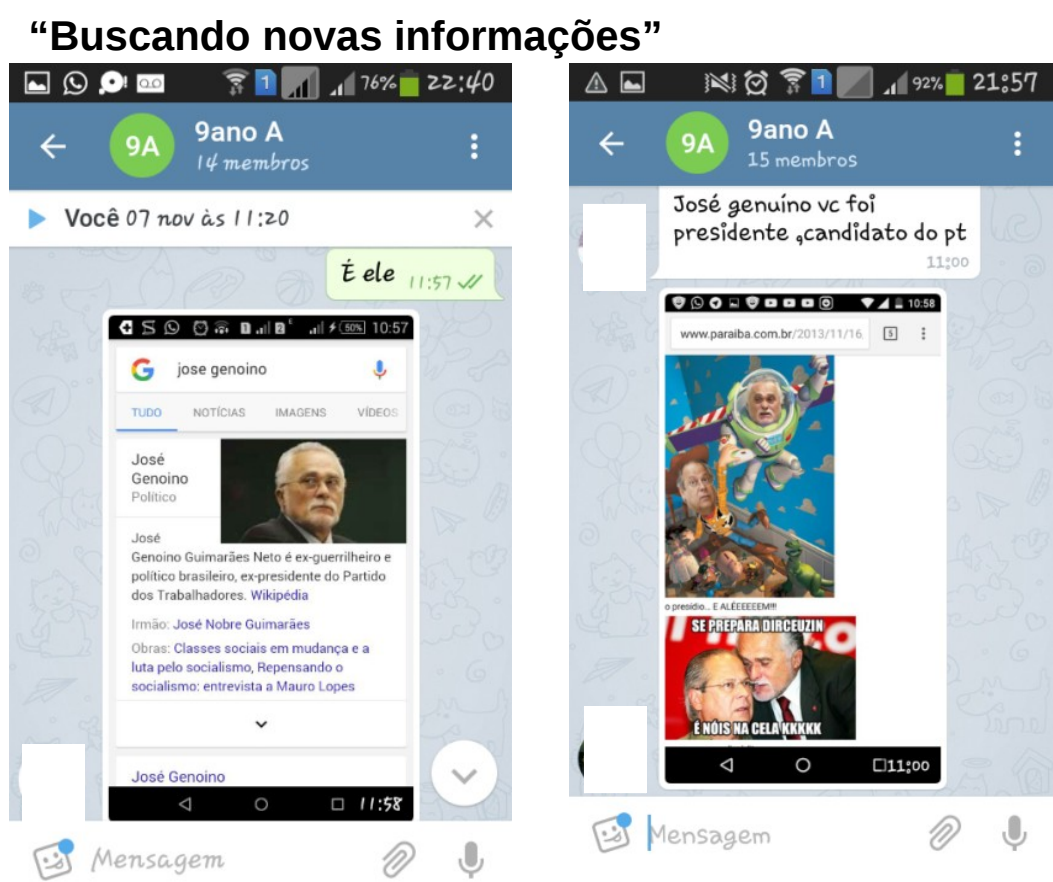

Figure 8: Busca na internet.

Figure 9: Conclusões dos alunos.

Fonte: das autoras. 
Em todos os momentos da aplicação da Sequência Didática, até a produção final, o aluno praticou a leitura e a escrita. A pesquisadora avaliou publicamente, em sala de aula, os progressos alcançados de forma aberta, inclusiva, considerando a multiplicidade de pontos de vista, colaborativamente, constatando se os elementos trabalhados ao longo da Sequência foram compreendidos.

No módulo da produção final, cada aluno teve a oportunidade de elaborar seu meme (Figura 10). A turma recebeu instruções da pesquisadora sobre como buscar sites de elaboração de memes na internet. Eles foram instruídos a selecionar um tema (o que dizer, a quem dizer), uma imagem e elaborar no smartphone um meme para postar no grupo. A partir das postagens, cada aluno no grupo pôde lançar comentários, interpretando os sentidos possíveis, explícitos e implícitos, a ironia e ou a conotação presentes nos textos elaborados, mobilizando todas as habilidades trabalhadas ao longo da Sequência Didática.

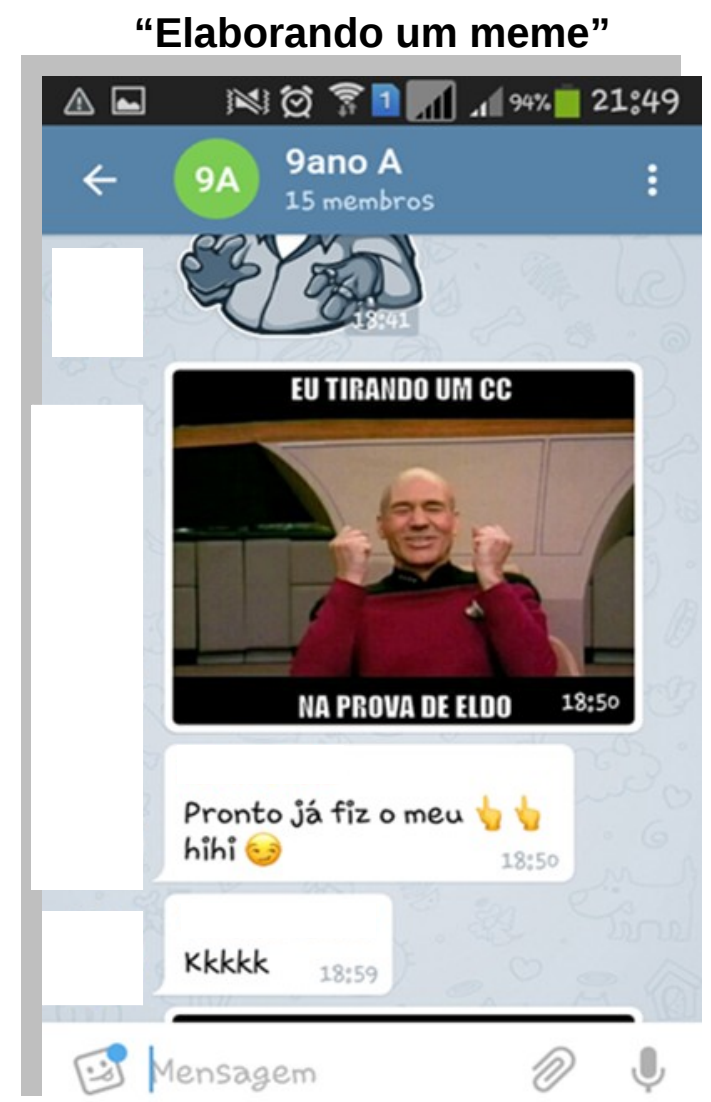

Figura 10: meme criado por aluno.

Fonte: das autoras.

Durante todo o processo, o letramento crítico foi incitado na construção de sentidos que se deu no processo de leitura, na busca, na seleção e no compartilhamento, na compreensão, na interpretação, na discussão e na produção escrita e multimodal dos memes. Com isso, pretendemos fomentar práticas comunicativas, visando à construção do letramento crítico em torno das temáticas que emergiram da leitura de memes, no ambiente virtual. 


\section{Considerações finais}

$\mathrm{Na}$ perspectiva do letramento crítico, a pesquisa lidou, a todo o momento, com posturas, ideias, percepções, posicionamentos, no intuito de convidar o aluno a expandir suas perspectivas de mundo e de conhecimento no seu processo de construção de sentidos. As diferentes temáticas envolveram questões abordadas nos memes, geralmente de forma bem humorada, permitindo, do ponto de vista dos conteúdos, estabelecer relações de sentido entre o local e o global, pertinentes à faixa etária dos alunos do $9^{\circ}$ ano do Ensino Fundamental. Do ponto de vista, da análise linguísticotextual, a proposta foi além de, meramente, identificar os elementos que compõem o humor e a ironia presentes nos memes, pois possibilitou aos alunos uma reflexão sobre os usos da linguagem e, principalmente, sobre as práticas que constituem os letramentos dos sujeitos na escola e na sociedade.

A Sequência Didática, focalizando o gênero digital meme, foi produtiva e proporcionou o adequado trabalho com descritores da Matriz de Referência para Língua Portuguesa. As atividades relatadas neste artigo são um singelo exemplo do que o professor de Língua Portuguesa pode fazer em sala de aula, para contemplar o trabalho com os textos multimodais e sua veiculação no ciberespaço, ao mesmo tempo em que fomenta o desenvolvimento de habilidades que colaboram para a construção do letramento crítico dos jovens alunos, corroborando os estudos de Janks (2016) e Takaki (2012).

Observamos na interação como cada aluno constrói sentidos e que o "espaço da sala de aula" se amplia e abre novas possibilidades de (re)construção do conhecimento para os alunos. Essa experiência reforçou a ideia de que o ensino precisa ser flexível, antenado e conectado com o mundo físico e virtual. Dessa forma, a escola, como agência de letramentos, pode contribuir para uma mudança significativa nas práticas de ensino e aprendizagem, auxiliando o processo de construção de múltiplos letramentos.

\section{Referências}

DOLZ, J.; NOVERRAZ, M. e SCHNEUWLY, B. Sequências didáticas para o oral e a escrita: apresentação de um procedimento. In: ROJO, R.; CORDEIRO, G. S. (Trad. e Org.). Gêneros orais e escritos na escola. Campinas, SP: Mercado de Letras, 2004, p. 95128.

FREIRE, P. Pedagogia do Oprimido. 17. ed. Rio de Janeiro: Paz e Terra, 1987.

HODGE, R.; KRESS, G. Social Semiotics. London: Polity Press, 1998.

JANKS, H. Panorama sobre o letramento crítico. In: JESUS, M.; CARBONIERI, D. (Org.) Práticas de multiletramentos e letramento crítico: outros sentidos para a sala de aula de línguas. Coleção: Novas perspectivas em Linguística Aplicada. v. 47. Campinas, SP: Pontes Editores, 2016. p. 21-39.

KRESS, G.; VAN LEEUWEN, T. Reading images: a grammar of visual design. London: 
Routledge. 1996.

KRESS, $G$ at al. Rhetorics of the science classroom: a multimodal approach. In: Multimodal teaching and learning. London: Continuum, 2001a. p. 10-41.

KRESS, G., VAN LEEUWEN, T. Multimodal Discourse. London: Arnold, 2001.

PALFREY, J.; GASSER, U. Nascidos na era digital: entendendo a primeira geração dos nativos digitais. Porto Alegre: Artmed, 2011.

SANTOS COSTA, G. Mobile Learning: Explorando potencialidades com o uso do celular no ensino - aprendizagem de língua inglesa como língua estrangeira com alunos da escola pública. 2013, 201f. Tese (Doutorado em Letras) - Centro de Artes e Comunicação, Universidade Federal de Pernambuco, Recife.

TAKAKI, N. H. Letramentos na sociedade digital: navegar é e não é preciso. Jundiaí: Paco Editorial, 2012.

TAKAKI, N. H.; MACIEL, R. F. (Org.). Letramentos em terra de Paulo Freire. 2. ed. Campinas, SP: Pontes Editores, 2015.

Recebido em dia 30 de agosto de 2018. Aprovado em dia 30 de outubro de 2018. 